\title{
Quand Lucky Luke et les (Amér)Indiens parlent francoprovençal bressan Traduction et transposition, entre inaudibilité linguistique et visibilité culturelle
}

\author{
Manuel Meune \\ Université de Montréal
}

Le francoprovençal (FP), parlé pendant des siècles dans quelques régions de France, de Suisse et d'Italie, ne compte plus que quelques dizaines de milliers de locuteurs, souvent âgés, qui appellent leur langue "patois". Sans statut officiel ni orthographe consensuelle, le FP peine à être reconnu par les autorités scolaires. Dans ce contexte, la traduction de bandes dessinées peut avoir une fonction éducative et favoriser la redécouverte d'une langue devenue inaudible. Elle peut même prendre la forme d'une traduction culturelle dépassant l'enjeu linguistique, comme nous le montrons en analysant le texte et le paratexte d'un album de Lucky Luke traduit vers le FP de Bresse (France), dans lequel le héros emblématique de la "BD western parodique" offre l'occasion de présenter des éléments de la culture bressane. En raison de la présence de personnages amérindiens, l'album traduit illustre les rapports que les cultures dominantes tant américaine que française entretiennent avec l'autochtonie (amérindienne ou "régionale"). Mais la démarche pose aussi la question de la légitimité de certaines transpositions; car le FP, certes ultra-minoritaire, reste associé à l'Occident colonisateur, et l'autochtonisation (bressanisation) du récit par des clins d'œil (noms de personnages et de lieux, proverbes, allusions aux chants, danses ou rituels de mariage bressans) n'inverse pas la perspective eurocentriste. Il reste que, bien qu'on puisse difficilement comparer une situation coloniale aux conséquences génocidaires en Amérique du Nord et une oppression sous forme d'assimilation lente en France, cette traduction peut nourrir la réflexion sur la condition autochtone de part et d'autre de l'Atlantique.

\section{Keywords}

traduction; bande dessinée; Amérindiens; Autochtones; stéréotypes; identité; western (genre);

revitalisation linguistique; langues minoritaires; francoprovençal 